Article

\title{
Evaluation of the Performance of Helmet Prototypes Fabricated from Acrylonitrile Butadiene Styrene Composites Filled with Natural Resource
}

\author{
Siti Nikmatin ${ }^{1, *}$, Bambang Hermawan ${ }^{1}$, Irmansyah Irmansyah ${ }^{1}$, Mohammad Nur Indro ${ }^{1}$, \\ Ahmad Beng Hong Kueh ${ }^{2,3}$ and Achmad Syafiuddin 4 (D) \\ 1 Department of Physics, Faculty of Mathematics and Natural Sciences, Bogor Agricultural University, \\ 16680 Bogor, Indonesia; bhermawan1000@gmail.com (B.H.); irmansyah@ipb.ac.id (I.I.); \\ mnindro@gmail.com (M.N.I.) \\ 2 Construction Research Centre (CRC), Institute for Smart Infrastructure and Innovative Construction (ISIIC), \\ Faculty of Engineering, Universiti Teknologi Malaysia, 81310 UTM Johor Bahru, Johor, Malaysia; \\ kbhahmad@utm.my \\ 3 Department of Civil Engineering, Faculty of Engineering, Universiti Malaysia Sarawak, \\ 94300 Kota Samarahan, Sarawak, Malaysia \\ 4 Department of Water and Environmental Engineering, Faculty of Engineering, Universiti Teknologi \\ Malaysia, 81310 UTM Johor Bahru, Johor, Malaysia; udenfisika@gmail.com \\ * Correspondence: snikmatin@apps.ipb.ac.id
}

Received: 20 November 2018; Accepted: 20 December 2018; Published: 22 December 2018

\begin{abstract}
The performance of helmet prototypes fabricated from acrylonitrile butadiene styrene composites filled with oil palm empty fruit bunch fibers was evaluated. The fibers were produced using a milling procedure, while the composites were fabricated using a single-screw extrusion. The physical characteristics of the produced fibers, which are water content, size, and density, were investigated. In addition, the mechanical properties of the produced helmets, including shock absorption, yield stress, frequency, and head injury criterion (HIC), were examined. The impact strength of the produced helmets increases with the rise of filler content. In addition, the helmets were also able to withstand a considerable pressure such that the transmitted pressure was far under the maximum value acceptable by the human skull. The present work also found that HICs exhibited by the investigated helmet prototypes fulfill all the practical guidelines as permitted by the Indonesian government. In terms of novelty, such innovation can be considered the first invention in Indonesia since the endorsement of the use of motorcycle helmets.
\end{abstract}

Keywords: oil palm; acrylonitrile butadiene styrene; natural fillers; mechanical properties

\section{Introduction}

Helmets have been widely worn as a form of protective headgear, with the primary goal of reducing the risk of injury caused by impact incidents [1-6]. Although the development of helmets is well-established, there is a motivated necessity for fabricating helmet shells that meet certain stringent safety requirements, especially with respect to improving their energy absorption. In particular, the capability of motorcycle safety helmets to absorb the impact energy is one of the critical factors for consideration to reduce severe injury. A well-performing helmet must concurrently protect the human skull and brain, since impact damage induced during a motorcycle accident can cause death. Realizing the life-threatening risk of such an event, the understanding of skull fractures and brain damage inflicted during accidents, including their protection measure, have been of utmost priority to fabricators. 
Several investigations have been carried out to study issues concerning head injury worldwide [7-11]. An investigation using 61 real-world accidents to evaluate the head injury criterion (HIC) and the head impact power (HIP), as well as the injury mechanisms, have been carried out [10]. These studies found that the moderate and severe neurological injuries cannot be distinguished solely on the global head acceleration, instead requiring a criterion computed using the intracranial variables. An experimental verification to identify the resonance frequencies of two kinds of freely vibrating human dry skulls and extrapolation of the results to living skulls by taking into account all known and estimated differences in mechanical properties has also been conducted [8]. Alternatively, a computational model employing the finite element model (FEM) to simulate the head injury was also proposed [7]. From these analyses, it was found that the composite shell systems exhibit lower shear performance, provide additional energy absorbing mechanisms, and result in better helmet crashworthiness behavior [9].

A good strategy to reduce the head injury during an accident is by involving a design with reputable criteria, as permitted by regulations given by a standardization. In order to improve the performance of helmets in terms of their energy absorption, recommendations for future helmets include the employment of materials that are capable of absorbing the impact energy during an accident, while keeping the acceleration transmitted to the head at a safe level. Therefore, it is constantly a great challenge to provide the right composition of helmet materials that have the proper set of mechanical properties. Several studies have reported that wearing helmets reduces fatalities by more than $25 \%[12,13]$. Moreover, it has been proven that non-helmeted motorcyclists are up to 3.4-fold more likely to die compared to helmeted riders in traffic crashes [14].

Recently, the exploration and utilization of natural materials have formed huge engineering and commercial interests [15-19]. This is because the use of natural composite materials provides many benefits, encompassing not only the environment but also economy and social aspects [20]. Along with cost-saving and ecological benefits such as improvement in $\mathrm{CO}_{2}$-balance, the main motivation driving these developments is related to the mechanical property profiles of natural materials, which offer reinforcement potential [21]. Furthermore, several studies have proven that the performance of some natural materials in fiber form is closely comparable to those of synthetic glass fibers [22]. Combined with the low-density of natural fillers, employing natural fiber composites results in lighter structures when compared to mineral-, short glass fiber-, long glass fiber-, and short carbon fiber-reinforced materials [23]. In addition, natural fiber composites can also be processed similarly to these different composite classes, such as by employing injection molding and extrusion techniques. In terms of processing, it was well established that natural fiber composites offer advantages in regard to equipment wear [23].

Considering the aforementioned concerns, the present work aims to evaluate the performance of helmet prototypes produced from acrylonitrile butadiene styrene composites filled with oil palm empty fruit bunch fibers. Up to this instance, the composite formed by this type of natural fiber has not been examined as a helmet material. The present study offers an investigation into the advantage of natural resources as fillers for advanced engineering applications. The present study reveals that the proposed helmet prototype is in general suitable for applications, as regulated by the Indonesian National Standardization (SNI). It is worth noting that such innovation can be considered the first invention in Indonesia since the introduction of the use of motorcycle helmets. The first Indonesian mandatory helmet law was enacted in 1984. In 1986, the Department of Transportation instituted a regulation making helmet usage mandatory for all motorcyclists. This development is expected to contribute to reducing head and neck injuries and deaths from motorcycle crashes. 


\section{Materials and Methods}

\subsection{Materials}

Oil palm empty fruit bunches (OPEFB) were collected from the PT Perkebunan Nusantara VIII Cikasungka, Bogor, Indonesia. Recycled and virgin acrylonitrile butadiene styrene (Torray Toyulac Resin 100MPJ40049689 NLG) were purchased from the PT MUB Jaya Cibinong, Bogor, Indonesia. A coupling agent, maleic anhydride, from Merck, Darmstadt, Germany was used in this work. In addition, an additive, antioxidant primer (butylated hydroxytoluene) from Tedia, Mumbai, India, was employed. The carvine 0331 Polyurethane 2K Z-331-039, carvine 0331 Polyurethane H-331-014, and carvine 0331.T-0378 were used for painting in three stages, namely, as the base, hardener, and thinner, respectively. The paints were supplied by the PT Murni Cahaya Pratama, Bogor, Indonesia. In addition, a polystyrene foam having a density of $33 \mathrm{~g} / \mathrm{cm}^{3}$, wrapped using fabric with a thickness of $10 \mathrm{~mm}$, and a visor fabricated using the polycarbonate were used to complete the overall structure of the helmet prototypes.

\subsection{Short Fibers Production}

The OPEFBs were initially washed using tap water to remove any impurities, and then immersed in tap water for $72 \mathrm{~h}$. To remove water content, the OPEFBs were dried under the sun for $24 \mathrm{~h}$, followed by oven (Xenaco, Guangzhou, China) drying at a temperature of $100{ }^{\circ} \mathrm{C}$ for $8 \mathrm{~h}$. The drying process was carried out such that the water content in the OPEFBs was less than $10 \%$. Short fiber filler production was carried out using a hammer mill (Model HMV-4W-5.5, PT MUB Jaya Cibinong, Bogor, Indonesia) with a rate of $5000 \mathrm{rpm}$ for $10 \mathrm{~min}$. Hammer milling is a mechanical treatment to minimize particle size with the combined actions of collision, shaking, and milling.

\subsection{Granular Production}

Composition of composites for the granular production for all helmet samples is listed in Table 1. It is noted that SN1, SN2, and SN3 refer to the helmets with filler content of $15 \%$ and recycled acrylonitrile butadiene styrene (ABS), filler content of $15 \%$ and virgin ABS, and filler content of $20 \%$ and recycled ABS, respectively. The granular composite was produced using the single-screw extruder machine (Model HXSJ-125/125, Kaixin, Nanjing, China). In the preparation, the filler, ABS, coupling agent, and additive were mixed at a speed of 15,000 rpm for $15 \mathrm{~min}$. The total mass of the sample was averagely measured as $50 \mathrm{~kg}$. The mixed samples were processed using the single-screw extruder machine and blended with gradient temperatures of $195,215,220,220,220,225,225$, and $225^{\circ} \mathrm{C}$.

Table 1. Material composition of the presently proposed helmets.

\begin{tabular}{ccccc}
\hline Type of Helmet & Filler (\%) & Type of ABS & Coupling Agent (\%) & Additive (\%) \\
\hline SN1 & 15 & Recycle & 2 & 1 \\
SN2 & 15 & Virgin & 2 & 1 \\
SN3 & 20 & Recycle & 2 & 1 \\
\hline
\end{tabular}

In this process, composites having a granular diameter of $3 \mathrm{~mm}$ were obtained. In addition, this process can produce composites having a water content of about $30 \%$. Next, the composites were dried under the sun for $24 \mathrm{~h}$ to reduce water content down to $13 \%$, followed by oven drying at a temperature of $80{ }^{\circ} \mathrm{C}$ for $3 \mathrm{~h}$ to have a further water content reduction down to $7 \%$. It is recommended that the water content of composites for helmet production using the molding injection machine is kept to be less than $10 \%$. 


\subsection{Helmet Production}

Helmet prototypes were then fabricated using an injection molding machine (Model HC-250, Hwa Chin, Tainan, China). In the barrel, the samples were blended with gradient temperatures of 195, $215,220,220,220,225,225$, and $225^{\circ} \mathrm{C}$. In addition, the helmets were painted in three stages, namely, for the base, hardener, and thinner. In addition, the polystyrene foam and visor were installed in all the helmets. In general, the helmets were produced according to the National Indonesia Standardization (SNI). For demonstration, various viewing perspectives for the presently fabricated helmet are shown in Figure 1.

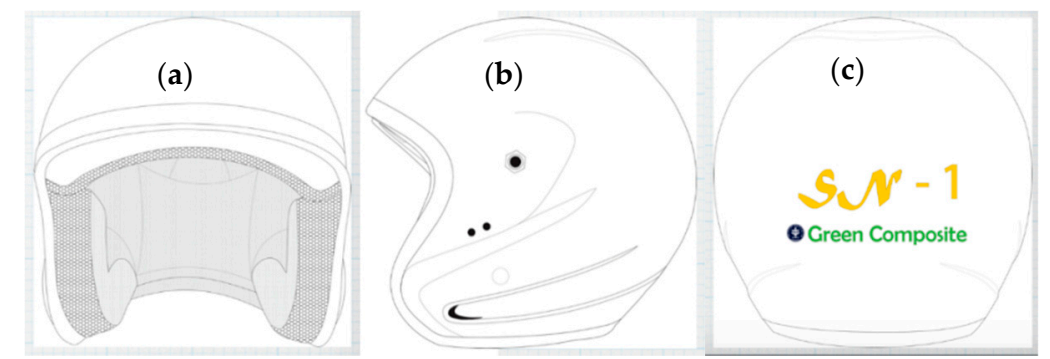

Figure 1. Design of the presently proposed helmet (a) front; (b) side and (c) back views.

\subsection{Shock Absorption Test}

A shock absorption test was performed using the uniaxial impact machine (CADEX, model 1000_00_MIMA, Cadex Inc., Saint-Jean-sur-Richelieu, QC, Canada). This test was carried out according to the Indonesian National Standardization (SNI 1811-2007). The test was performed in three repetitions. Two different anvil types were employed for the test, i.e., hemispherical and flat. The hemispherical anvil has a spherical surface radius of $48 \mathrm{~mm}$, constituting one-half of the surface of a full sphere. The flat anvil has a flat surface of minimum side dimensions of $125 \mathrm{~mm}$ and a thickness of $24 \mathrm{~mm}$. Additionally, Flat-1 and Flat-2 anvils refer to the anvil dropped from $5 \mathrm{~m}$ and $3 \mathrm{~m}$ in height, respectively.

\subsection{Yield Stress Estimation}

The yield stress was estimated using the procedure proposed by Mills and Gilchrist [24]. It can be computed by considering the contact geometry between a flat impactor and the spherical outer surface of the foam liner. If the amount of liner crush, $x$, is less than the radius of curvature, $R$, of the spherical outer surface, the contacted area, $A$, can be estimated using $A=2 \pi R x$. If the impact is applied to a hemispherical anvil, the equation must be modified as Equation 1:

$$
A=2 \pi x\left(\frac{1}{R_{1}}+\frac{1}{R_{2}}\right)^{-1}
$$

where $R_{1}$ and $R_{2}$ are the radii of the helmet and anvil, respectively. It has been assumed that the foam yields over an area, $A$, of radius, $a$, with a constant yield stress, $\sigma$. The force transmitted by the foam can be estimated by $F=A \sigma$. Therefore, the yield stress can be estimated using the following equation:

$$
\sigma=\frac{m a}{A}
$$

where $m$ is the mass of the helmet and head dummy and $a$ is the acceleration of the helmet and anvil. 


\subsection{Frequency Analysis}

In this analysis, a mass-spring-mass model developed by Gao and Wampler [25] was adopted. In general, it begins by applying Newton's second law of motion and Hooke's law formulas as:

$$
m a=-k x
$$

By defining a function of the position of mass with respect to time as $x(t)=A \cos (\omega t)$, Equation (3) becomes:

$$
\left(\frac{k}{m}-\omega^{2}\right)(A \cos (\omega t))=0
$$

It can be obtained from Equation 4 that $\omega=\sqrt{k / m}$. Since $\omega=2 \pi f$, the frequency, $f$, can be estimated using the following equation:

$$
f=\frac{1}{2 \pi} \sqrt{\frac{k^{*}}{m}} \text { with } k^{*}=\frac{k_{1} k_{2}}{k_{1}+k_{2}}
$$

where $m$ is the total mass of the helmet and head dummy and $k_{1}$ and $k_{2}$ are the stiffness constants of the helmet and head dummy, respectively.

\subsection{Head Injury Criterion Analysis}

A head injury can be defined as any incident that results in trauma to the skull or brain. Among all injury criteria, HIC is the most globally used for measuring the severity of injury in the cases where the human head is engaged as the impacted mass. By measuring the energy required to cause concussive effects, a limit between impact intensities causing fatal and non-fatal injuries can be determined. The analytical expression of HIC is described by the following equation [25]:

$$
\mathrm{HIC}=\left(\left[\frac{1}{t_{2}-t_{1}} \int_{t_{1}}^{t_{2}} \hat{a}(t) d t\right]_{\max }^{2.5}\left(t_{2}-t_{1}\right)\right)
$$

where $t_{1}$ and $t_{2}$ are the initial and final times (in seconds) of the interval, during which HIC attains a maximum value, and acceleration, $\hat{a}$, is measured in gs (standard gravity acceleration). It is useful to note that the measurement in gs means that $\hat{a}$ is $a / g$, with $a$ as the head acceleration and $g$ as the acceleration of gravity in any compatible units. Therefore, $\hat{a}$ is defined as the normalized head acceleration. As an alternative, the overall normalized impact resistance index can be estimated for comparative purposes $[26,27]$.

\section{Results and Discussion}

\subsection{Physical Properties of the Produced Fibers}

The drying process carried out in this work is useful to ensure that the water content of the oil palm short fibers is less than $10 \%$. They were $58.0 \%, 17.4 \%$, and $7.2 \%$ for before drying, after drying under the sun, and after drying in an oven, respectively. It is noticeable that the lowest water content, which was less than $10 \%$, can be obtained using the presently employed method. Figure 2 shows the morphology of the oil palm short fibers. The length and diameter of the short fibers were $230.1 \pm 95.3 \mu \mathrm{m}$ and $58.5 \pm 23.0 \mu \mathrm{m}$, respectively. These values were obtained by the measurement of random samples using an optical microscopy. 


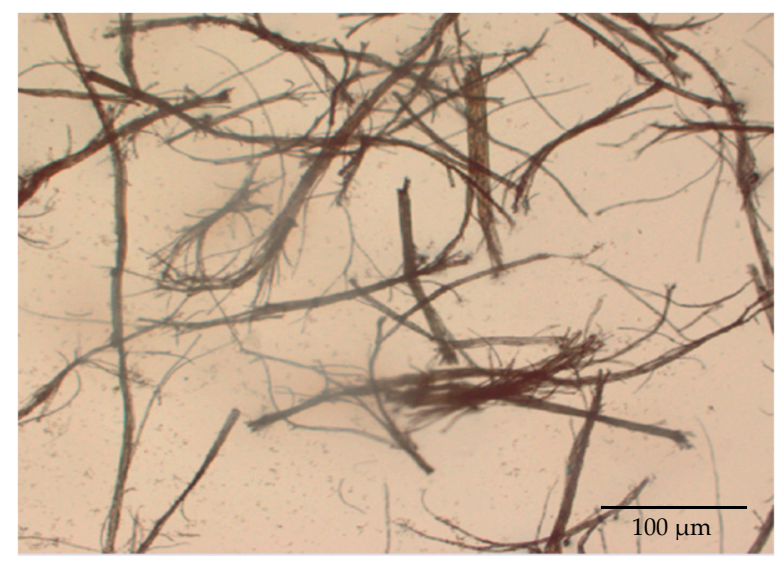

Figure 2. Morphology of the currently produced OPEFB.

Table 2 presents the densities of OPEFBs for different studies [28-32]. It is noticeable that the densities reported by various researchers are not identical because of the variation in the kind of oil palm fiber used. In addition, there exists some fluctuation in the irregular sectional areas, causing the length determination difference of OPEFBs [33]. Nevertheless, the current study found that the density of the produced fibers was in an acceptable range with those obtained from the previous works. Various investigations have reported that the densities of OPEFB fibers are in the range of 0.7 to $1.55 \mathrm{~g} / \mathrm{cm}^{3}$, less than that of glass fiber, which is $2.6 \mathrm{~g} / \mathrm{cm}^{3}$. This suggests that using OPEFB fibers as the reinforcement of a composite can reduce its total mass compared to the use of glass fiber. Therefore, studies on the exploration of OPEFB fibers as an alternative for glass fiber have been popular and of high potential for applications.

Table 2. Densities of the studied filler from various works.

\begin{tabular}{cccc}
\hline Type of Oil Palm Fiber & Density $\left(\mathbf{g} / \mathbf{c m}^{\mathbf{3}}\right)$ & Country & Reference \\
\hline Short fibers & 0.7 to 1.55 & India & Sreekala et al. [31] \\
Short fibers & 1.03 & India & Rao and Rao [30] \\
Short fibers & 1.4 & India & Joseph et al. [28] \\
Short fibers & 1.03 & India & Rao and Rao [30] \\
Short fibers & 1.15 & Malaysia & Yusoff et al. [32] \\
Short fibers & 1.15 & Indonesia & Karina et al. [29] \\
Short fibers & 1.35 & Indonesia & Present work \\
\hline
\end{tabular}

\subsection{Helmet Prototype}

Helmets produced from ABS composites filled with OPEFB fibers following the SNI 1811-2007 standardization can be well-expected to improve in their physical-mechanical properties, particularly in terms of good impact energy absorption during traffic accidents. Figure 3 shows the prototype of the presently produced helmet. In order to get an attractive appearance, the helmet was also painted. Helmet assembly was done by adding a layer of expanded polystyrene (EPS), soft lining, and other accessories required in accordance with SNI 1811-2007. 

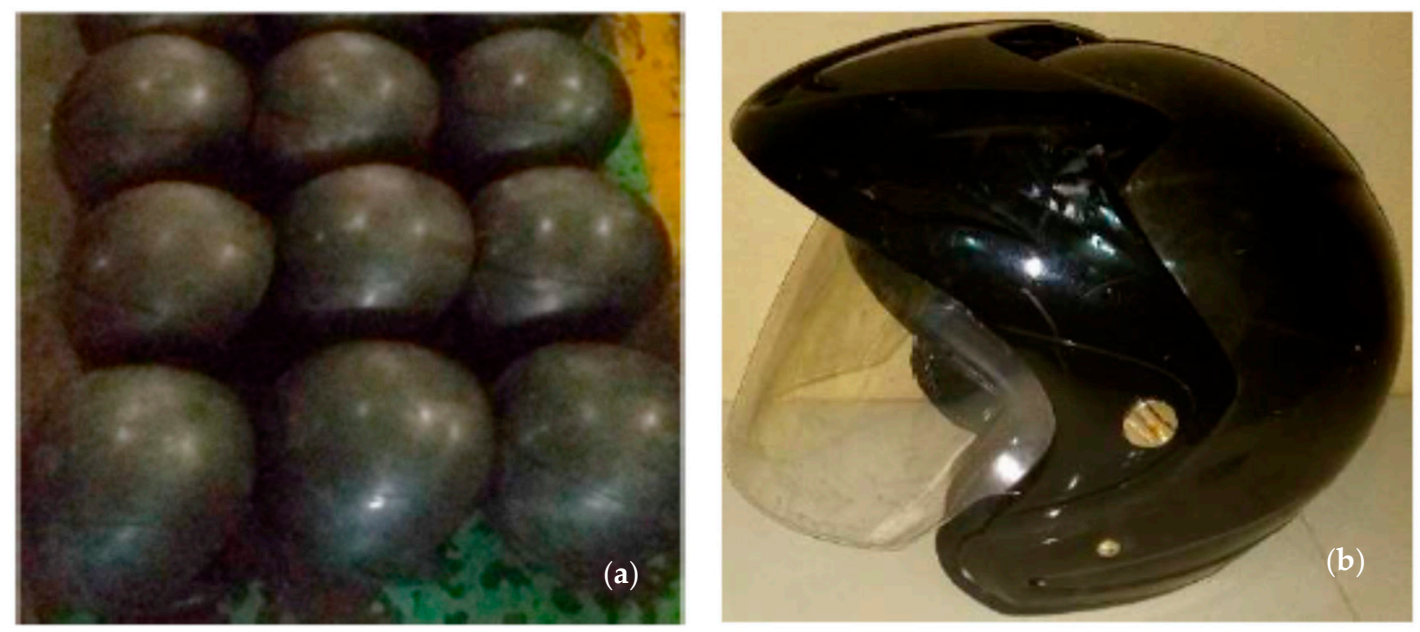

Figure 3. Presently proposed helmet prototype: (a) above and (b) side views.

\subsection{Mechanical Properties}

Composite granules were used to produce the helmet specimens using the molding machine. Table 3 lists the impact characteristics of the helmets. As previously mentioned, all testing was conducted according to the SNI. The test was carried out at three different temperatures. This study found that the impacts of SN1 at a temperature of $-20{ }^{\circ} \mathrm{C}$ were in the range of 81.3 to $121.7 \mathrm{G}$. In addition, their impacts at a temperature of $50{ }^{\circ} \mathrm{C}$ were in the range of 113.2 to $137.9 \mathrm{G}$.

Table 3. Impact characteristics of the currently produced helmets.

\begin{tabular}{|c|c|c|c|c|}
\hline Code & Temperature $\left({ }^{\circ} \mathrm{C}\right)$ & Clash Position & Anvil Type & Impact (G) \\
\hline \multirow{6}{*}{ SN1 } & \multirow{3}{*}{-20} & \multirow[b]{2}{*}{ Backside } & Flat-1 & 121.7 \\
\hline & & & Flat-2 & 103.6 \\
\hline & & Topside & Hemispherical & 81.3 \\
\hline & \multirow{3}{*}{50} & \multirow{2}{*}{ Backside } & Flat-1 & 137.9 \\
\hline & & & Flat-2 & 113.2 \\
\hline & & Topside & Hemispherical & 127.4 \\
\hline \multirow{6}{*}{ SN2 } & \multirow{3}{*}{-20} & \multirow{2}{*}{ Backside } & Flat-1 & 151.7 \\
\hline & & & Flat-2 & 133.6 \\
\hline & & Topside & Hemispherical & 86.1 \\
\hline & \multirow{3}{*}{50} & \multirow{2}{*}{ Backside } & Flat-1 & 130.3 \\
\hline & & & Flat-2 & 122.2 \\
\hline & & Topside & Hemispherical & 101.7 \\
\hline \multirow{6}{*}{ SN3 } & \multirow{3}{*}{-20} & \multirow{2}{*}{ Backside } & Flat-1 & 317.1 \\
\hline & & & Flat-2 & 357.2 \\
\hline & & Topside & Hemispherical & 310.2 \\
\hline & \multirow{3}{*}{50} & \multirow[b]{2}{*}{ Backside } & Flat-1 & 240.5 \\
\hline & & & Flat-2 & 270.5 \\
\hline & & Topside & Hemispherical & 230.1 \\
\hline
\end{tabular}

As a comparison, the impact values for SN2 tested at temperatures of $-20{ }^{\circ} \mathrm{C}$ and $50{ }^{\circ} \mathrm{C}$ ranged from 86.1 to $151.7 \mathrm{G}$ and 101.7 to $130.3 \mathrm{G}$, respectively. In addition, the corresponding values for SN3 were 310.2 to $357.2 \mathrm{G}$ and 230.1 to $270.5 \mathrm{G}$, respectively. It was found that the impact values for SN3 were higher compared to SN1 and SN2. Increase in the impact strength was possibly due to the increase in the filler content for SN3 (20\%) compared to SN1 (15\%) and SN2 (15\%). Findings of this study are similar with those obtained from the previous works. For instance, increasing filler contents (snail shell powder) from $0 \%$ to $40 \%$ increased the impact strength of the produced composites [34]. 
A similar observation was also obtained when the composite material of low-density polyethylene (LDPE) as the base was mixed with raw kaolin [35]. From the relevant study, it was found that increasing the filler content from $5 \%$ to $15 \%$ increases their composite strength from 0.3 to $0.5 \mathrm{~kJ} / \mathrm{m}^{2}$. An increase in the impact strength can be attributed to the elastic behavior of the added filler contents, which have high toughness and extendibility without a permanent deformation [36]. Moreover, the current study has confirmed that the produced helmets offer good performance according to the SNI in terms of their impact strength performance.

\subsection{Yield Stress and Frequency}

The stress yields for SN1 were found to be in the range of 0.99 to $1.32 \mathrm{MPa}$ and 25.94 to $40.65 \mathrm{MPa}$ when the produced helmets were tested at temperatures of $-20{ }^{\circ} \mathrm{C}$ and $50{ }^{\circ} \mathrm{C}$ using the flat and hemispherical anvils, respectively. At $-20{ }^{\circ} \mathrm{C}$, the frequency range was 50.74 to $94.21 \mathrm{~Hz}$, while it was from 53.04 to $81.99 \mathrm{~Hz}$ at $50{ }^{\circ} \mathrm{C}$. In summary, the yield stress and frequency characteristics of SN2 and SN3 are presented in Table 4 (detailed computation is provided in the supporting document, A1).

Table 4. Yield stress and frequency of the tested helmets.

\begin{tabular}{|c|c|c|c|c|c|}
\hline Code & Temperature $\left({ }^{\circ} \mathrm{C}\right)$ & Clash Position & Anvil Type & Yield Stress (MPa) & Frequency (Hz) \\
\hline \multirow{6}{*}{ SN1 } & \multirow{3}{*}{-20} & \multirow{2}{*}{ Backside } & Flat-1 & 1.17 & 54.99 \\
\hline & & & Flat-2 & 0.99 & 50.74 \\
\hline & & Topside & Hemispherical & 25.94 & 44.95 \\
\hline & \multirow{3}{*}{50} & \multirow{2}{*}{ Backside } & Flat-1 & 1.32 & 58.54 \\
\hline & & & Flat-2 & 1.08 & 53.04 \\
\hline & & Topside & Hemispherical & 40.65 & 56.26 \\
\hline \multirow{6}{*}{ SN2 } & \multirow{3}{*}{-20} & \multirow{2}{*}{ Backside } & Flat-1 & 1.45 & 61.4 \\
\hline & & & Flat-2 & 1.28 & 57.62 \\
\hline & & Topside & Hemispherical & 27.48 & 46.25 \\
\hline & \multirow{3}{*}{50} & \multirow{2}{*}{ Backside } & Flat-1 & 1.25 & 56.9 \\
\hline & & & Flat-2 & 1.17 & 55.1 \\
\hline & & Topside & Hemispherical & 32.45 & 50.27 \\
\hline \multirow{6}{*}{ SN3 } & \multirow{3}{*}{-20} & \multirow{2}{*}{ Backside } & Flat-1 & 3.04 & 88.77 \\
\hline & & & Flat-2 & 3.42 & 94.21 \\
\hline & & Topside & Hemispherical & 98.99 & 87.80 \\
\hline & \multirow{3}{*}{50} & \multirow{2}{*}{ Backside } & Flat-1 & 2.30 & 77.31 \\
\hline & & & Flat-2 & 2.59 & 81.99 \\
\hline & & Topside & Hemispherical & 73.43 & 75.62 \\
\hline
\end{tabular}

\subsection{HIC Characteristics}

Based on ASTM-F1292-04, the time interval for evaluation for impact performance is restricted to a maximum of $15 \mathrm{~ms}$, and HIC $<1000$ is known as a critical value for avoiding fatal injuries to the human head. This implies that a very high head acceleration is tolerable for a brief period of time. The probabilities of brain injury at different HIC scores are documented in the ASTM-F1292-04 standardization as listed in Table 5. The values shown emphasize the importance of proper and effective protection. 
Table 5. Head injury criteria.

\begin{tabular}{ccccc}
\hline HIC Score & Moderate Injury (\%) & Moderate Injury (\%) & Critical Injury (\%) & Fatal (\%) \\
\hline 0 & 0 & 0 & 0 & 0 \\
250 & 40 & 20 & 0 & 0 \\
500 & 80 & 40 & 2 & 0 \\
750 & 95 & 70 & 4 & 0 \\
1000 & 98 & 90 & 8 & 2 \\
1250 & 100 & 95 & 10 & 2 \\
1500 & 100 & 98 & 20 & 4 \\
1750 & 100 & 100 & 45 & 10 \\
2000 & 100 & 100 & 70 & 30 \\
2250 & 100 & 100 & 90 & 70 \\
2500 & 100 & 100 & 95 & 90 \\
2750 & 100 & 100 & 98 & 95 \\
3000 & 100 & 100 & 100 & 100 \\
\hline
\end{tabular}

HIC scores of the presently proposed helmet are presented in Table 6. In addition, HIC curve examples of the prototype helmet with testing temperatures of $-20^{\circ} \mathrm{C}$ and $50{ }^{\circ} \mathrm{C}$ are shown in Figure 4 . HIC scores were found in the range of 804.69 to 828.38 when the helmets were tested at $-20{ }^{\circ} \mathrm{C}$. At $50{ }^{\circ} \mathrm{C}$, the HICs were in the range of 769.63 to 792.75 . Based on the HIC listed in the table, it is ratified that the presently proposed helmet can be categorized as offering good protection, with a $95 \%$ chance of minor injury, $70 \%$ chance of moderate injury, and $4 \%$ chance of critical injury. For a comprehensive overview, HIC characteristics of SN2 and SN3 are also presented in Table 6. Therefore, it is obvious that the proposed helmet has a great conformity with the Indonesian standard, SNI 1811-2007. This is because SNI 1811-2007 has regulated that the permitted HIC is $<3000$.

Table 6. Head injury criteria of the presently proposed helmets.

\begin{tabular}{|c|c|c|c|c|}
\hline Code & Temperature $\left({ }^{\circ} \mathrm{C}\right)$ & Clash Position & Anvil Type & HIC \\
\hline \multirow{6}{*}{ SN1 } & \multirow{3}{*}{-20} & \multirow{2}{*}{ Backside } & Flat-1 & 760 \\
\hline & & & Flat-2 & 398 \\
\hline & & Topside & Hemispherical & 335 \\
\hline & \multirow{3}{*}{50} & \multirow[b]{2}{*}{ Backside } & Flat-1 & 799 \\
\hline & & & Flat-2 & 433 \\
\hline & & Topside & Hemispherical & 453 \\
\hline \multirow{6}{*}{ SN2 } & \multirow{3}{*}{-20} & \multirow[b]{2}{*}{ Backside } & Flat-1 & 1141 \\
\hline & & & Flat-2 & 662 \\
\hline & & Topside & Hemispherical & 334 \\
\hline & \multirow{3}{*}{50} & \multirow{2}{*}{ Backside } & Flat-1 & 980 \\
\hline & & & Flat-2 & 587 \\
\hline & & Topside & Hemispherical & 411 \\
\hline \multirow{6}{*}{ SN3 } & \multirow{3}{*}{-20} & \multirow{2}{*}{ Backside } & Flat-1 & 904 \\
\hline & & & Flat-2 & 858 \\
\hline & & Topside & Hemispherical & 694 \\
\hline & \multirow{3}{*}{50} & \multirow{2}{*}{ Backside } & Flat-1 & 591 \\
\hline & & & Flat-2 & 595 \\
\hline & & Topside & Hemispherical & 603 \\
\hline
\end{tabular}



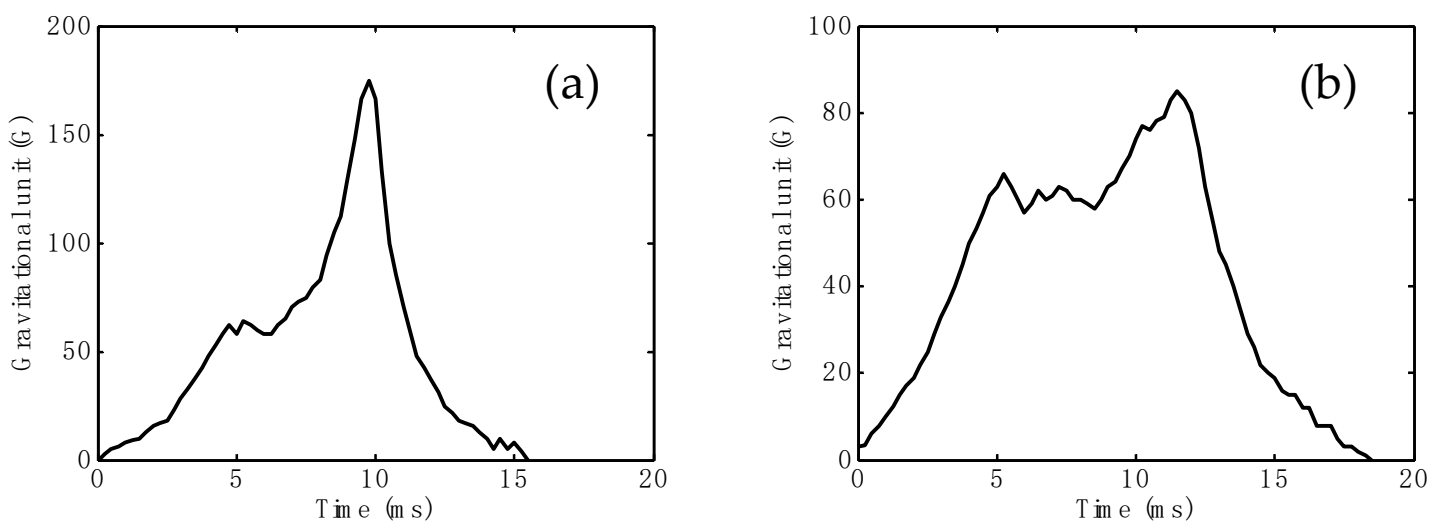

Figure 4. Typical head injury criterion curves in accordance with SN1, with testing conditions of (a) $-20^{\circ} \mathrm{C}$ and (b) $50^{\circ} \mathrm{C}$. Other data for SN2 and SN3 are provided in the supporting document, A1.

\section{Conclusions}

This study was carried out to evaluate the performance of helmet prototypes produced from acrylonitrile butadiene styrene composites filled with oil palm empty fruit bunch fibers. The mechanical properties of constituents for the helmet prototype have been characterized and presented. The presently fabricated fiber has a water content of less than $10 \%$, density of $1.35 \mathrm{~g} / \mathrm{cm}^{3}$, fiber length of $230.1 \pm 95.3 \mu \mathrm{m}$, and fiber diameter of $58.5 \pm 23.0 \mu \mathrm{m}$. The impact values for SN3 were the highest compared to SN1 and SN2, suggesting an improved impact strength for a higher filler content. Furthermore, it was also found that all HICs produced by the helmet prototypes were $<850$, as permitted by the SNI regulation. In closing, the prototype helmets are in practical agreement and conform to the Indonesian standard, SNI 1811-2007.

Supplementary Materials: The following are available online at http:/ /www.mdpi.com/1996-1944/12/1/34/s1.

Author Contributions: S.N. conducted the experiments and contributed to the drafting of the manuscript. I.I., B.H., M.N.I., and A.B.H.K. involved in the data analysis. A.S. and A.B.H.K. involved in the interpretation of results and contributed to the critical discussion. All authors reviewed and approved the manuscript.

Funding: The present work was funded by the Indonesian Ministry of Research, Technology and Higher Education under the scheme of Penelitian Terapan Unggulan Perguruan Tinggi (PTUPT). Collaboration and support from the Indonesia Oil Palm Estate Fund (Badan Pengelola Dana Perkebunan Kelapa Sawit [BPDPKS]), Ministry of Finance, Republic of Indonesia are highly appreciated.

Acknowledgments: The authors thank the Bogor Agricultural University for facilitating the research work.

Conflicts of Interest: The authors declare no conflict of interest.

\section{References}

1. Aiello, M.; Galvanetto, U.; Iannucci, L. Numerical simulations of motorcycle helmet impact tests. Int. J. Crashworthiness 2007, 12, 1-7. [CrossRef]

2. Chang, L.T.; Chang, G.L.; Huang, J.Z.; Huang, S.C.; Liu, D.S.; Chang, C.H. Finite element analysis of the effect of motorcycle helmet materials against impact velocity. J. Chin. Inst. Engrs. 2003, 26, 835-843. [CrossRef]

3. Farajzadeh Khosroshahi, S.; Galvanetto, U.; Ghajari, M. Optimization of the chin bar of a composite-shell helmet to mitigate the upper neck force. Appl. Compos. Mater. 2017, 24, 931-944. [CrossRef]

4. Fernandes, F.A.O.; Alves de Sousa, R.J. Motorcycle helmets-A state of the art review. Accid. Anal. Prev. 2013, 56, 1-21. [CrossRef] [PubMed]

5. Ghajari, M.; Galvanetto, U.; Iannucci, L.; Willinger, R. Influence of the body on the response of the helmeted head during impact. Int. J. Crashworthiness 2011, 16, 285-295. [CrossRef]

6. Rueda, M.A.F.; Gilchrist, M.D. Computational analysis and design of components of protective helmets. Proc. Inst. Mech. Eng. Pt. P J. Sports Eng. Tech. 2012, 226, 208-219.

7. Chang, C.-H.; Chang, L.-T.; Chang, G.-L.; Huang, S.-C.; Wang, C.-H. Head Injury in facial impact-A finite element analysis of helmet chin bar performance. J. Biomech. Eng. 2000, 122, 640-646. [CrossRef] [PubMed] 
8. Khalil, T.B.; Viano, D.C.; Smith, D.L. Experimental analysis of the vibrational characteristics of the human skull. J. Sound Vib. 1979, 63, 351-376. [CrossRef]

9. Kostopoulos, V.; Markopoulos, Y.P.; Giannopoulos, G.; Vlachos, D.E. Finite element analysis of impact damage response of composite motorcycle safety helmets. Compos. Part B Eng. 2002, 33, 99-107. [CrossRef]

10. Marjoux, D.; Baumgartner, D.; Deck, C.; Willinger, R. Head injury prediction capability of the HIC, HIP, SIMon and ULP criteria. Accid. Anal. Prev. 2008, 40, 1135-1148. [CrossRef]

11. Yoganandan, N.; Pintar, F.A. Biomechanics of temporo-parietal skull fracture. Clin. Biomech. 2004, 19, 225-239. [CrossRef] [PubMed]

12. Evans, L.; Frick, M.C. Helmet effectiveness in preventing motorcycle driver and passenger fatalities. Accid. Anal. Prev. 1988, 20, 447-458. [CrossRef]

13. Rutledge, R.; Stutts, J. The association of helmet use with the outcome of motorcycle crash injury when controlling for crash/injury severity. Accid. Anal. Prev. 1993, 25, 347-353. [CrossRef]

14. Braddock, M.; Schwartz, R.; Lapidus, G.; Banco, L.; Jacobs, L. A population-based study of motorcycle injury and costs. Ann. Emerg. Med. 1992, 21, 273-278. [CrossRef]

15. Nikmatin, S.; Syafiuddin, A.; Irwanto, D.A.Y. Properties of oil palm empty fruit bunch-filled recycled acrylonitrile butadiene styrene composites: Effect of shapes and filler loadings with random orientation. BioResources 2016, 12, 1090-1101. [CrossRef]

16. Nikmatin, S.; Syafiuddin, A.; Kueh, A.B.H.; Purwanto, Y.A. Effects of nanoparticle filler on thermo-physical properties of rattan powder-filled polypropylene composites. Jur. Tek. 2015, 77, 181-187. [CrossRef]

17. Syafiuddin, A.; Hadibarata, T.; Kueh, A.B.H.; Salim, M.R. Novel weed-extracted silver nanoparticles and their antibacterial appraisal against a rare bacterium from river and sewage treatment plan. Nanomaterials 2018, 8, 9. [CrossRef] [PubMed]

18. Syafiuddin, A.; Hadibarata, T.; Salim, M.R.; Kueh, A.B.H.; Sari, A.A. A purely green synthesis of silver nanoparticles using Carica papaya, Manihot esculenta, and Morinda citrifolia: Synthesis and antibacterial evaluations. Bioprocess Biosyst. Eng. 2017, 40, 1349-1361. [CrossRef]

19. Syafiuddin, A.; Salmiati, S.; Jonbi, J.; Fulazzaky, M.A. Application of the kinetic and isotherm models for better understanding of the behaviors of silver nanoparticles adsorption onto different adsorbents. J. Environ. Manag. 2018, 218, 59-70. [CrossRef]

20. Nikmatin, S.; Syafiuddin, A.; Hong Kueh, A.B.; Maddu, A. Physical, thermal, and mechanical properties of polypropylene composites filled with rattan nanoparticles. J. App. Res. Technol. 2017, 15, 386-395. [CrossRef]

21. Sobczak, L.; Lang, R.W.; Haider, A. Polypropylene composites with natural fibers and wood-General mechanical property profiles. Compos. Sci. Technol. 2012, 72, 550-557. [CrossRef]

22. Vilaseca, F.; Valadez-Gonzalez, A.; Herrera-Franco, P.J.; Pèlach, M.À.; López, J.P.; Mutjé, P. Biocomposites from abaca strands and polypropylene. Part I: Evaluation of the tensile properties. Bioresour. Technol. 2010, 101, 387-395. [CrossRef] [PubMed]

23. Zampaloni, M.; Pourboghrat, F.; Yankovich, S.; Rodgers, B.; Moore, J.; Drzal, L.; Mohanty, A.; Misra, M. Kenaf natural fiber reinforced polypropylene composites: a discussion on manufacturing problems and solutions. Compos. Part. A Appl. Sci. Manuf. 2007, 38, 1569-1580. [CrossRef]

24. Mills, N.J.; Gilchrist, A. The effectiveness of foams in bicycle and motorcycle helmets. Accid. Anal. Prev. 1991, 23, 153-163. [CrossRef]

25. Gao, D.; Wampler, C.W. Head injury criterion. IEEE Robot. Autom. Mag. 2009, 16, 71-74. [CrossRef]

26. Abo Sabah, S.H.; Kueh, A.B.H.; Al-Fasih, M.Y. Bio-inspired vs. conventional sandwich beams: A low-velocity repeated impact behavior exploration. Constr. Build. Mater. 2018, 169, 193-204. [CrossRef]

27. Abo Sabah, S.H.; Kueh, A.B.H.; Al-Fasih, M.Y. Comparative low-velocity impact behavior of bio-inspired and conventional sandwich composite beams. Compos. Sci. Technol. 2017, 149, 64-74. [CrossRef]

28. Joseph, S.; Kenny, J.M.; Puglia, D.; Thomas, S.; Joseph, K. Oil palm microcomposites: Processing and mechanical behavior. Polym. Eng. Sci. 2010, 50, 1853-1863. [CrossRef]

29. Karina, M.; Onggo, H.; Abdullah, A.D.; Syampurwadi, A. Effect of oil palm empty fruit bunch fiber on the physical and mechanical properties of fiber glass reinforced polyester resin. J. Biol. Sci. 2008, 8, 101-106.

30. Rao, K.M.M.; Rao, K.M. Extraction and tensile properties of natural fibers: Vakka, date and bamboo. Compos. Struct. 2007, 77, 288-295. [CrossRef] 
31. Sreekala, M.S.; George, J.; Kumaran, M.G.; Thomas, S. The mechanical performance of hybrid phenol-formaldehyde-based composites reinforced with glass and oil palm fibres. Compos. Sci. Technol. 2002, 62, 339-353. [CrossRef]

32. Yusoff, M.Z.M.; Salit, M.S.; Ismail, N.; Wirawan, R. Mechanical properties of short random oil palm fibre reinforced epoxy composites. Sains. Malays. 2010, 39, 87-92.

33. Virk, A.S.; Hall, W.; Summerscales, J. Failure strain as the key design criterion for fracture of natural fibre composites. Compos. Sci. Technol. 2010, 70, 995-999. [CrossRef]

34. Onuegbu, G.C.; Igwe, I.O. The effects of filler contents and particle sizes on the mechanical and end-use properties of snail shell powder filled polypropylene. Mater. Sci. Appl. 2011, 2, 811-817. [CrossRef]

35. Mallik, A.; Barik, A.K.; Pal, B. Comparative studies on physico-mechanical properties of composite materials of low density polyethylene and raw/calcined kaolin. J. Asian Ceram. Soc. 2015, 3, 212-216. [CrossRef]

36. Ruksakulpiwat, Y.; Sridee, J.; Suppakarn, N.; Sutapun, W. Improvement of impact property of natural fiber-polypropylene composite by using natural rubber and EPDM rubber. Compos. Part. B Eng. 2009, 40, 619-622. [CrossRef]

(C) 2018 by the authors. Licensee MDPI, Basel, Switzerland. This article is an open access article distributed under the terms and conditions of the Creative Commons Attribution (CC BY) license (http:/ / creativecommons.org/licenses/by/4.0/). 